\section{О МЕЖКУЛЬТУРНОЙ ОСВЕДОМЛЕННОСТИ \\ СТУДЕНТОВ-РУСИСТОВ \\ (НА МАТЕРИАЛЕ ЭМПИРИЧЕСКИХ ДАННЫХ)}

\author{
ABOUT CROSS-CULTURAL AWARENESS \\ OF RUSSIAN FILOLOGY STUDENTS (BASED ON EMPIRICAL DATA)
}

АННА ЖЕБРОВСКА

\begin{abstract}
In the age of a rapid development of technology and communication intercultural education plays a special role. The goal of this education is to develop and shape intercultural competence. A purposeful and carefully considered process is needed to achieve this. The process consists of several stages, of which the most important is teaching/learning a foreign language based on the student's native language and culture. This means that, apart from knowing certain elements of another culture, a student should have a thorough knowledge of his/her own country, history and culture. However, it often turns out that students know more about the culture of a given foreign country and nation than about their own culture. The study presented in this article confirms this hypothesis, and thus clearly emphasizes the need for improving the content of the syllabus as well as the methods of teaching foreign languages in Polish educational centers.
\end{abstract}

Anna Żebrowska, Uniwersytet im. Adama Mickiewicz w Poznaniu, Poznań - Polska.

На сегодняшний момент считается, что межкультурное образование является одной из актуальнейших тем методического пространства. Суть межкультурного образования заключается в приобретении обучающимися индивидуального опыта общения с иной лингвокультурой. При этом необходимо помнить, что межкультурное обучение осуществляется на основании родного языка и культуры, собственного мировидения и миропонимания. Подобный подход к обучению иностранному языку позволяет учащимся выявить в культурах общие и национально-специфические черты; более глубоко осознать не только чужую, но и свою культуру, свой язык, а также „вникнуть в языковую «картину мира» двух народов, понять их психологию, характер, обычаи, обряды, историю, нашедшую в этой картине мира своеобразное воплощение" 1 .

1 Л.Г. С а я х о в а, Спецкурс „Язык и культура" в системе профессиональной подготовки студентов-филологов. Язык и культура. Учебное пособие по спецзкурсу, Уфа 1995, с. 14. 
Межкультурное образование заключает в себе несколько этапов, позволяющих в итоге формировать и развивать межкультурную компетенцию, которая, в свою очередь, является целью межкультурного образования. Итак, во-первых, необходимо усвоить фоновую информацию о фактах иной культуры на контрастной основе; во-вторых, уметь ее не только воспринимать, но и анализировать и интерпретировать в зависимости от межкультурного контекста; в-третьих, в процессе учения/обучения проигрывать межкультурные ситуации, переменно выполняя различные роли. Реализация вышеперечисленных этапов осуществима исключительно в ходе разрешения конфликтных межкультурных ситуаций, к которым, вслед за А.Л. Бердичевским, будем относить:

- культурные различия в вербальной коммуникации, напр. социальное значение понятий, „табу"-темы в различных культурах, особенности использования тех или иных речевых актов (извинение, благодарность, скрытость, прямота, откровенность и т.п.);

- культурные различия в невербальной коммуникации, напр. в телодвижениях - рукопожатия, поклоны, объятия, поза и дистанция при беседах, зрительный контакт, мимика, жесты и т.д.;

- культурные различия в паравербальной коммуникации, напр. уровень громкости речи в зависимости от ситуации; модуляция голоса при произношении вопросительных, восклицательных, повествовательных предложений и др.

Как видим, для успешного общения представителей разных культур недостаточно ориентироваться лишь в чужой культуре - необходимо обладать основательными знаниями в области собственных языка и культуры. Этот факт существен как для филолога, так и для представителя любой другой специальности, желающего вступить в диалог с иностранцем. Однако нас, как преподавателей иностранного языка, заинтересовала межкультурная осведомленность студентов-русистов, которую мы попытались определить посредством анкетирования. Целесообразно добавить, что часть анкетных результатов (наличие и уровень сведений о русской культуре) была представлена нами на конференции в Люблине 2 , в настоящий же момент мы обратимся к ним с точки зрения межкультурного образования. Это позволит увидеть, насколько польские студенты, будущие специалисты по русскому языку, сориентированы не только в русской культуре, но и в своей род-

2 I Международная научно-практическая методическая конференция из цикла „Современная русистика в формировании единого культурного и информационного пространства Европы": Обучение русскому языку студентов филологических и нефилологических факультетов вузов, 7-10.06.2009 г., Люблин. 
ной; указать пробелы в знаниях студентов и сделать соответствующие выводы, которые, в свою очередь, могут стать „подсказкой” в поисках более эффективных и плодотворных методик обучения.

В анкетировании приняли участие студенты I-IV курсов, в общем количестве 200 человек (по 50 на каждом курсе). Среди опрошенных оказалось несколько студентов другой национальности (два студента русской с родным языком русским, два польской с родным русским языком, один белорус с родным языком русским, два студента украинской национальности, один из которых родным языком назвал русский, а другой - и русский, и украинский, и один армянин с родным армянским языком). Остальные информанты - представители польского языка и культуры. Здесь следует отметить, что согласно полученным ответам не наблюдается особого различия во взглядах студентов польской национальности и представителей иного лингвокультурного пространства. Это, в свою очередь, свидетельствует о том, что мировоззрение индивидуума формирует общество, с которым он сосуществует и которое передает ему свои устоявшиеся нормы, правила и традиции.

Итак, студентам была предложена анкета, состоявшая из шести вопросов. Сперва мы хотели бы обратить внимание на два последних (Как Вы познакомились с Россией/Польшей? Были ли Вы в России/Польше? Если „да", то сколько раз? Как долго Вы находились в России/Польше? Что Вам особенно запомнилось из Вашей поездки?). Если говорить о знакомстве с Россией, то оно прежде всего проходило посредством СМИ, занятий в школе, в университете, художественной литературы, а также личного знакомства с Россией, причем студенты, побывавшие в России, диаметрально меняли свое отношение к русским, отходя от шаблонного мышления и стереотипного представления о русской национальности. Что касается Польши, то поляки здесь родились, а студенты других национальностей проживают уже несколько лет на ее территории.

Среди анкетных вопросов особый интерес представляют для нас четыре первых, поскольку они позволяют наглядно увидеть и оценить межкультурную осведомленность будущих специалистов-русистов.

Анализируя ответы на первый вопрос анкеты (Какие ассоциации вызывает у Вас слово „Россия” / „Польша”?), нетрудно заметить, что „Россия" ассоциируется в основном с искусством (студентами называются фамилии русских поэтов и писателей: А.С. Пушкин, Ф.М. Достоевский, Л.Н. Толстой, М.Ю. Лермонтов и др.; имена композиторов: С.В. Рахманинов, П.И. Чайковский и т.п.; архитектурные памятники: Собор Василия Блаженного, Кремль, Зимний дворец и ряд других памятников). Слово „Польша” вызывает подобные ассоциации (с искусством), только не в таком значительном количестве перечисляются 
имена польских творцов (среди них, напр., А. Мицкевич, Ю. Словацки и Иоанн Павел II). Вторую группу, выделенную на основании ответов, образуют слова-ассоциации, обращающиеся к истории (русской: Петр I, Иван Грозный, Ленин, Сталин, лагеря, ссылки; польской: Вторая мировая война, коммунизм); третью - понятия, связанные с ситуацией на современной политической арене (в России: отсутствие свободы слова, Путин, антиевропейская политика и т.п.; в Польше: политические споры, братья Качиньские, Валенса, Солидарность и т.д.). Очередную группу ассоциаций составили географические названия, среди которых наиболее повторяющимися оказались: из русских наименований - Москва, Санкт-Петербург, Сибирь, Байкал, Волга; из польских - Татры, Балтийское море, Варшава, Краков. В пятой группе мы сконцентрировались на словах, характеризующих повседневную жизнь россиян и поляков. Жизнь россиян определяется студентами как полная контрастов, богатства, золота и нищеты, бедности, всеобщего беспорядка и распространенного алкоголизма; обыденность поляков имеет подобную характеристику: безработица, бедность, алкоголизм, беспорядок, нетолерантность. Кроме того, как у русской, так и польской национальности отмечалось необыкновенное гостеприимство. Отдельную группу составили определения типа: Россия - огромная страна, могущественная держава, соседка Польши, суровый климат, русские березы и т.д.; Польша - моя Родина, семья, дом, центр Европы, гордость и т.П., которые мы отнесли к категории под названием „другие ответы”. Среди высказываний нашлись также ответы „Не знаю” и „Отсутствие ответов", однако таких анкет, в которых студенты не высказывались или же признавались в отсутствии ассоциаций, оказалось немного (1-3 ответа на двести опрошенных), причем относится это как к слову „Россия”, так и к слову „Польша". Сравнительный анализ ассоциаций, вызванных словом "Россия" / „Польша”, показывает, что польские студенты отличаются лучшими знаниями в области русской культуры и реалий, чем в своих собственных.

Подтверждением сказанному являются также ответы на вопрос, предлагающий перечислить деятелей искусства, науки, политики и т.п., которые, по мнению студентов, внесли особый вклад в развитие русской/ польской культуры.

В ходе анализа студенческих высказываний стало возможным выявление пяти кластеров. В первый вошли фамилии известнейших деятелей культуры (писателей, поэтов, композиторов, художников, режиссеров, философов и т.д.); во второй - исторические личности и политические деятели; третью группу образовали „другие ответы” (фамилии ученых, спортсменов, журналистов); четвертую - ответы „не знаю"; пятую - отсутствие высказываний, большинство которых встре- 
чается на первом курсе, однако их незначительное количество. Здесь, как и в предыдущем случае, польские студенты перечислили преобладающее число русских творцов, исторических и политических лиц, что еще раз указывает на недостаточную ориентировку в собственной культуре.

Свидетельствуют о вышесказанном и ответы на очередные вопросы анкеты: характеристика интеллектуальных возможностей русских/поляков, их отношения к другим, внешнего вида, а также питания и кухни.

Интеллектуальные возможности русских и поляков оцениваются польскими студентами примерно одинаково. Преобладают положительные ответы (у русских: большие интеллектуальные возможности, это начитанные, одаренные, образованные, умные, творческие и т.п. люди; у поляков: большой потенциал, умные, интеллигентные, способные и т.д.), хотя образовалась группа и отрицательных (у русских чаще всего отмечается лень и низкий уровень образования, а у поляков - снижение уровня образования и слабое знание иностранных языков). При этом студенты нередко отмечали, что национальность не имеет значения; люди способные, но не у всех есть возможность учиться; все зависит от личных способностей человека (такого рода суждения мы причислили к кластеру „другие ответы”). Необходимо добавить, что не все студенты смогли высказать свое мнение касательно умственного потенциала русских. Из 200 опрошенных 16 человек не оценило возможностей русских, дав ответ „не знаю” или оставив рубрику без отзыва. Относительно потенциала поляков в пяти анкетах встретился ответ „не знаю” и в двух - отсутствие ответа.

Рассматривая в сравнительном аспекте ответы на следующий вопрос (Характеристика эмоциональной стороны русских / поляков и их отношения к другим), видим, что польские студенты русскую национальность оценивают позитивнее, чем свою. Из положительных черт и русских, и поляков чаще всего называлась доброжелательность, открытость, искренность, гостеприимство; из отрицательных - нетолерантность, вспыльчивость, равнодушие. В группу „другие ответы” вошли такие характеристики, как: все зависит от ситуации, в которой оказывается человек; бывают разные - открытые и замкнутые, равнодушные и чувствительные; мы, поляки, часто руководствуемся стереотипами. В ответах на данный вопрос также встречалось „не знаю” и отсутствие ответов.

Исключением не стало и описание внешнего вида русских/поляков. Русских не смогло охарактеризовать 19 студентов (в 9 анкетах отсутствует ответ, а в 10 дан ответ „не знаю”), поляков - тоже 19 (12 - отсутствие ответов, 7 - „не знаю”). Свой внешний вид поляки оценивают 
положительнее, чем вид русских, подчеркивая аккуратность, привлекательность, вкус, стиль, элегантность и красоту своей нации. Преобладающее количество ответов мы отнесли к группе „другие ответы”. В нее вошла сравнительная характеристика русских/поляков и других национальностей, напр., русские: ничем не отличаются от жителей Европы; русские и поляки похожи; краснощекие, полноватые; интенсивный макияж и много золота; поляки - европейцы; разные, национальность не имеет значения; каждая культура и каждый живущий в ней человек неповторимы; высокие, худощавые, голубоглазые; не надевают так много золота как русские и т.д.

Следующим этапом анкетирования стало задание охарактеризовать русскую/польскую кухню. Были получены такие положительные ответы, как: русская кухня - вкусная, разнообразная; польская -великолепная, здоровая, традиционная. Отрицательных высказываний о русской кухне не встречалось, а польскую респонденты нередко называли нездоровой и жирной. Из русских блюд многократно повторялись: блины, пельмени, щи; из польских: bigos, rosół, pierogi, żurek. Давались также определения типа: разнообразная кухня, много овощей и фруктов, много мучных изделий, водка и т.п. В ряде случаев встречались ответы „не знаю” или полное отсутствие ответов.

Представленный до сих пор материал, по нашему мнению, показывает отношение молодых поляков как к русским, так и к самим себе, а также фиксирует уровень межкультурной осведомленности в тех или иных аспектах. Практически ответы на каждый вопрос, с одной стороны, констатируют рост знаний в области русской культуры, что неудивительно, поскольку это факультет русской филологии, а с другой стороны, подчеркивают недостаточную осведомленность о своих культурных ценностях. Еще одним доказательством сказанному является следующий вопрос, предложенный студентам: перечислить известные им русские/ польские праздники и традиции.

В итоге перед нами предстала следующая картина: русских традиций и праздников не смогло назвать большинство первокурсников; на втором, третьем и четвертом курсе встречались единичные случаи отсутствия ответов или ответы „не знаю”. Респонденты показали совсем неплохие знания, сумев перечислить немалое количество русских / польских праздников и традиций (русские: Новый год, Масленица, День Победы и др.; польские: Wszystkich Świętych, Andrzejki, Boże Narodzenie и т.д.). Однако, несмотря на это, стоит отметить, что от первого курса, а в некоторых моментах и от остальных, следовало бы ожидать лучшего, притом не только по отношению к русской культуре, но и к польской. 
Таким образом, проанализированные материалы указывают на парадокс и подтверждают положение: студенты русской филологии зачастую обладают более основательными знаниями о русской культуре, чем о родной. Свидетельствует это о том, что нам, и теоретикам и практикам, необходимо искать новые содержания, средства, методы, повышающие уровень межкультурного образования, а тем самым формирующие и совершенствующие межкультурную компетенцию студентов-русистов, позволяющую им эффективно применять полученные знания на практике, т.е. в аутентичных ситуациях межкультурного общения. 
